\title{
Identification of concentration points of finance and investment resources in the regions
}

\author{
Maria Rakhova $^{1}$, and Maria Zakirova ${ }^{1, *}$ \\ ${ }^{1}$ Vladimir State University named after Alexander and Nikolay Stoletovs, Gorkogo str, 79, Vladimir, \\ 600005, Russia
}

\begin{abstract}
The purpose of the paper is to assess the sufficiency of the financial and investment resources of the territory to increase its potential, and the possibility of the overflow of this resource to neighboring socioeconomic systems. The study substantiates the need to identify the resource potential of the regions in order to determine opportunities for their development and reduce dependence on external economic and political influence. In the paper, in particular, the sufficiency of financial and investment resources of the central federal district is determined, which include the production factor "capital", including investments in fixed assets, costs for research and development and technological innovations. The research method is based on the normalization, correlation and factor analysis of the initial data, and consists in calculating the accumulation norms and coefficients of significance of the selected resources. The results of identifying concentration points can be applied in the future to assess the prospects for economic development of the regions of the central federal district. The results of research can be useful to federal and regional executive authorities for the formulation and adjustment of the planned development strategy.
\end{abstract}

\section{Introduction}

At present, due to the difficult economic situation in Russia, in order to overcome the acute resource shortage, the main task is the innovative socially oriented development of the economy of all sectors. The relevance is also caused by the sanctions impact on the national economy of several Western countries on resource strings. In this connection, one of the priority directions for the development of the country by the Government of the Russian Federation is the course of import substitution [1-4]. The positive moment of this impact is the strategy of intensification of the available resources of the territories. However, such an impact on the regional economy is impossible without the full use of available resources: labor, material, financial, natural, etc. [5]. In view of the specific features of Russia, such as a large territorial extent and, consequently, a rich variety of both types of resources and conditions for their use, the issues of not only quantitative and qualitative assessment of regional reserves, but also the conditions of their use become very relevant. At the same time, as rightly notes Dr. of Sc. M.B. Petrov, confirming the earlier

* Corresponding author: zakirova maria@mail.ru 
findings of Dr. Sc. A.G. Greenberg, the emphasis in this matter should fall at the regional level, since this is facilitated by qualitative differences on certain grounds between subjects and the historically established integrity of the elements of such a territory [6]. The socioeconomic system of Russia, changing over the last period not only quantitatively but also qualitatively, has all the necessary resources to solve most economic and social constraints. Thus, the issue of assessing the ability of regions to provide reproduction processes to ensure import substitution is quite relevant.

\section{Materials}

O.Yu. Mereshchenko in her study emphasizes that the success of the functioning and development of each region is largely determined by the availability of resources, their structure, update rate, efficiency of use [7]. In collaboration with E. Bessonova, they offer a methodology for assessing the resource potential with regard to import substitution, which precludes a two-level analysis and allows evaluating resource potential in the region and optimal economy sectors for development [8].

Based on the classical theory of the structure of production factors, which includes such factors as: labor, land, capital and entrepreneurship, this study will analyze the adequacy of financial and investment flows (the production factor "capital"). The production factor "capital" consists, in our opinion, first of all, from a set of financial and investment flows, ensuring not only the flow of socio-economic processes with a certain level of efficiency, but also generating reproduction relations. Which promote further growth not only in quantitative but also in qualitative measurement. In addition to direct investments in the development of the economy, the financing of individual projects (including socially significant ones), the maintenance and development of infrastructure, and the replacement of physically or morally obsolete fixed assets may be attributed to such flows.

From our point of view, in order to ensure the optimal functioning of the region under the conditions of the ongoing innovation and modernization processes, a single territory that has clear geographical boundaries must be provided with all types of resources to the maximum extent possible. This can be explained by the fact that under the conditions of an external restriction, to which it becomes possible to attribute the imposed economic sanctions, socio-economic systems may face both a general shortage and a deficit of certain types of resources. In the case of the existence of internal reserves, such a limitation may trigger a new qualitative growth. As noted by E.A. Ploskonosova, "in the context of the priorities analysis, it is important, first of all, to determine the initial direction of effort's concentration that can push to the reversal of the entire modernization process" [9]. For the full use of this kind of capabilities in the territory of a single subject of the federation, the presence of all the above elements and systems is necessary. As noted by Professor O.S. Sukharev "the structure of investments in different types of technologies affects the level of technological effectiveness of the economy and its change. This should be taken into account when developing policies aimed at forming a new model of industrial growth for the Russian economy, engineering and the commodity sector" [10].

In this case, it is possible to distinguish some subsystems of the resource potential as strategic, i.e. more priority. Such a selection, in our opinion, should be made on the basis of the current specialization and development history. As a rule, a strategic resource should be, if not the basis, then an important aspect of the competitiveness of a region, i.e. its qualitative and quantitative components should differ from similar ones in adjacent territories with a different industrial specialization [11-12]. The main problem is, in our opinion, the selection of the qualitative state of the element of regional resource potential, specifically, the efficiency of using a particular stock. 


\section{Results}

Since the realization of the resource potential is impossible without timely and sufficient provision of the necessary financial and investment resources, it is proposed in this work to analyze the sufficiency of their provision using the example of the Central Federal District regions. The empirical base of the research is provided by economic and statistical materials of the Federal State Statistics Service, which characterize the socio-economic development of the subjects of the Russian Federation. A study to assess the adequacy of financial and investment resources that form the production factor "capital" for the effective use of the resource potential of a territory is carried out on the basis of the following four indicators: investment in fixed capital (K1), internal costs of research and development (K2), and technological innovation (K3), investment in fixed capital per capita (K4). It is possible to assess the level of influence of the above factors on the final result by calculating the correlation coefficients of factors relative to the gross regional product (GRP) of the region and the average incomes of the population (AIP), respectively. An example of this calculation for the Vladimir region is presented in table 1.

Table 1. Verification of the integrity of the factor structure of the financial and investment block of the resource potential using the example of the Vladimir region.

\begin{tabular}{|c|c|c|c|}
\hline $\begin{array}{l}\text { The } \\
\text { production } \\
\text { factor } \\
\text { "capital" }\end{array}$ & Indicator & $\begin{array}{c}\text { The correlation } \\
\text { coefficients (for } \\
\text { GRP) }\end{array}$ & $\begin{array}{c}\text { The correlation } \\
\text { coefficient (AIP) }\end{array}$ \\
\hline $\begin{array}{c}\text { investment in } \\
\text { fixed capital }\end{array}$ & $\mathrm{K} 1$ & 0.99 & 0.971 \\
\hline $\begin{array}{c}\text { internal costs of } \\
\text { research and } \\
\text { development }\end{array}$ & $\mathrm{K} 2$ & 0.99 & 0.996 \\
\hline $\begin{array}{c}\text { costs of } \\
\text { technological } \\
\text { innovation }\end{array}$ & $\mathrm{K} 3$ & 0.95 & 0.953 \\
\hline $\begin{array}{c}\text { investment in } \\
\text { fixed capital per } \\
\text { capita }\end{array}$ & $\mathrm{K} 4$ & 0.99 & 0.973 \\
\hline
\end{tabular}

Analysis of the obtained values (Table 1) indicates a rather strong influence of the selected indicators on the total, since all values are close to unity.

In order to confirm the socio-economic unity of the selected indicators in the work, their factor load was calculated. The final results of the factor analysis are presented in table 2 .

Table 2. The results of the factor analysis

\begin{tabular}{|c|c|}
\hline Indicator & Factor loading \\
\hline K1 & -0.991 \\
\hline K2 & -0.991 \\
\hline K3 & -0.963 \\
\hline K4 & -0.990 \\
\hline Prp. Totl. & 0.97 \\
\hline
\end{tabular}

Thus, the selected set of indicators describes $97 \%$ of the total variability, i.e. this group of factors is a single socio-economic phenomenon. Therefore, it is possible to use the selected set of factors to determine the availability of a strategic resource in the region [13]. 
In order to solve the problem of differences in units of measurement, at the first stage of this survey, the indicators were normalized. At the same time, the normalized indicator was calculated as the ratio of the indicator's actual value of the $i$-th region in the $j$-th period to the indicator's maximum value among all the analyzed regions in the $\mathrm{j}$-th period.

At the second stage, the coefficients of resource significance were calculated in two sub-steps. First, the calculation of the accumulation rate for each indicator of the resource potential of the region was made according to the equation (1):

$$
N_{i j}=\frac{X_{n, i j}-X_{n-1, i j}}{X_{n, i j}}
$$

where $N$ - the rate of accumulation of the resource;

$X n, i j$ - the value of the stock of the $i$-th resource of the $j$-region in the time period $n$;

$X n-1, i j$ - the value of the stock of the $i$ - $t h$ resource of the $j$-region in the time period $n-1$.

Following the above logic, the calculation was made for all indicators. The calculation results for indicator $\mathrm{K} 1$ are presented in table 3 .

Table 3. The example of calculating the rate of accumulation of the resource K1

\begin{tabular}{|c|c|c|c|c|c|c|}
\hline Region & $\mathbf{2 0 1 1}$ & $\mathbf{2 0 1 2}$ & $\mathbf{2 0 1 3}$ & $\mathbf{2 0 1 4}$ & $\mathbf{2 0 1 5}$ & $\mathbf{2 0 1 6}$ \\
\hline CFD & 0.15 & 0.17 & 0.11 & 0.07 & 0.03 & 0.03 \\
\hline Belgorod region & 0.24 & 0.08 & -0.06 & -0.07 & 0.18 & -0.02 \\
\hline Bryansk region & 0.13 & -0.03 & 0.24 & 0.08 & -0.07 & 0.10 \\
\hline Vladimir region & 0.16 & 0.02 & 0.07 & 0.12 & 0.08 & -0.03 \\
\hline Voronezh region & 0.19 & 0.15 & 0.16 & 0.10 & 0.09 & 0.03 \\
\hline Ivanovo region & 0.07 & -0.13 & 0.15 & -0.03 & -0.29 & -0.13 \\
\hline Kaluga region & 0.04 & 0.19 & 0.02 & 0.02 & -0.08 & -0.16 \\
\hline Kostroma region & 0.14 & 0.17 & 0.05 & 0.19 & -0.05 & 0.01 \\
\hline Kursk region & 0.21 & 0.12 & 0.07 & 0.03 & -0.05 & 0.22 \\
\hline Lipetsk region & 0.10 & -0.21 & 0.08 & 0.04 & 0.09 & 0.09 \\
\hline Moscow region & 0.12 & 0.13 & 0.12 & 0.09 & -0.01 & -0.01 \\
\hline Oryol region & 0.37 & 0.16 & 0.08 & 0.08 & 0.09 & -0.09 \\
\hline Ryazan region & 0.24 & 0.20 & 0.12 & -0.25 & -0.12 & -0.06 \\
\hline Smolensk region & 0.14 & -0.01 & -0.01 & 0.01 & 0.06 & 0.00 \\
\hline Tambov region & 0.21 & 0.18 & 0.16 & 0.11 & 0.10 & -0.15 \\
\hline Tver region & 0.12 & -0.17 & 0.00 & 0.04 & -0.13 & 0.17 \\
\hline Tula region & 0.08 & 0.08 & 0.08 & 0.04 & 0.10 & 0.06 \\
\hline Yaroslavl region & 0.10 & 0.01 & 0.06 & 0.02 & -0.28 & 0.16 \\
\hline Moscow city & 0.14 & 0.30 & 0.14 & 0.08 & 0.04 & 0.05 \\
\hline
\end{tabular}

Note that a negative value for a number of periods in some regions means a decrease in the indicator compared with the previous period.

Secondly, the calculation of the coefficient of significance of resources $\mathrm{k}$ was made from the following positions:

$$
k=1+l
$$

moreover, if $N_{F D i}>N i_{j r e g}$, then $l=0$ - the analyzed type of resource is not strategic (the subject does not specialize in its formation and use);

if $N_{F D i}<N_{i j \text { reg }}$, then use equation (3)

$$
l=\frac{1}{n}
$$


where $l$ - the significance of a specific type of resource;

$n$ - the number of indicators in a particular block of resource potential.

In total, the research of the production factor "capital" block examines 4 indicators, i.e. the calculation takes the form

$$
l=\frac{1}{n}=\frac{1}{4}=0.25
$$

For example, in 2011 in the Belgorod region, there is the following inequality $0.15<$ 0.24 , the accumulation rate of the $K 1$ resource in the region is more than the district, therefore we use the equation (2):

$$
k_{1}^{B e \lg \operatorname{Re} g}=1+0.25=1.25
$$

Consequently, this resource for the Belgorod region in 2011 is a strategic one.

Similarly, the calculation of the coefficients $K$ for all regions of the Central Federal District for the period 2011-2016 was made. Results for 2011 and 2016 are presented in table 4.

Table 4. Resource significance factors K.

\begin{tabular}{|l|l|l|l|l|l|l|l|l|}
\hline \multirow{2}{*}{ Region } & \multicolumn{2}{c|}{ K$_{1}$} & \multicolumn{2}{c|}{ K$_{2}$} & \multicolumn{2}{c|}{ K3 $^{2}$} & \multicolumn{2}{c|}{ K4 $^{*}$} \\
\cline { 2 - 10 } & $\mathbf{2 0 1 1}$ & $\mathbf{2 0 1 6}$ & $\mathbf{2 0 1 1}$ & $\mathbf{2 0 1 6}$ & $\mathbf{2 0 1 1}$ & $\mathbf{2 0 1 6}$ & $\mathbf{2 0 1 1}$ & $\mathbf{2 0 1 6}$ \\
\hline CFD & 1.25 & 1 & 1 & 1 & 1 & 1.25 & 1.25 & 1 \\
\hline Belgorod & 1 & 1.25 & 1.25 & 1.25 & 1 & 1.25 & 1 & 1.25 \\
\hline Bryansk & 1.25 & 1 & 1 & 1.25 & 1 & 1 & 1.25 & 1 \\
\hline Vladimir & 1.25 & 1 & 1 & 1 & 1.12 & 1 & 1.25 & 1 \\
\hline Voronezh & 1 & 1 & 1.25 & 1 & 1 & 1 & 1 & 1 \\
\hline Ivanovo & 1 & 1 & 1.25 & 1 & 1 & 1 & 1 & 1 \\
\hline Kaluga & 1 & 1 & 1 & 1 & 1 & 1 & 1.25 & 1 \\
\hline Kostroma & 1.25 & 1.25 & 1 & 1.25 & 1.1 & 1.25 & 1.25 & 1.25 \\
\hline Kursk & 1 & 1.25 & 1.25 & 1 & 1 & 1.25 & 1 & 1.25 \\
\hline Lipetsk & 1 & 1 & 1.25 & 1 & 1 & 1 & 1 & 1 \\
\hline Moscow & 1.25 & 1 & 1.25 & 1.25 & 1 & 1.1 & 1.25 & 1 \\
\hline Oryol & 1.25 & 1 & 1 & 1 & 1 & 1 & 1.25 & 1 \\
\hline Ryazan & 1 & 1 & 1 & 1.25 & 1 & 1 & 1.25 & 1 \\
\hline Smolensk & 1.25 & 1 & 1 & 1 & 1 & 1.25 & 1.25 & 1 \\
\hline Tambov & 1 & 1.25 & 1 & 1.25 & 1 & 1.25 & 1 & 1.25 \\
\hline Tver & 1 & 1.25 & 1 & 1.25 & 1 & 1.25 & 1 & 1.25 \\
\hline Tula & 1 & 1.25 & 1.25 & 1.25 & 1 & 1 & 1 & 1.25 \\
\hline Yaroslavl & 1 & 1.25 & 1 & 1.25 & 1.1 & 1.25 & 1 & 1.25 \\
\hline Moscow city & 1.25 & 1 & 1 & 1 & 1 & 1.25 & 1.25 & 1 \\
\hline
\end{tabular}

*regions with existence of a strategic resource on all 4 indicators in 2016 are highlighted in bold type, italics - on three indicators

The results of calculating the coefficients of significance of financial and investment resources for the four indicators testify to their concentration in 2016 in the Bryansk, Kursk, Tver and Tula regions, and in the city of Moscow. Note that in the Lipetsk and Yaroslavl regions, there is also a concentration of these resources, not counting the indicator "internal costs of research and development", the value of which decreased only at the end of the survey period. Based on the data obtained, it is possible to form an 
estimate of the probability of using the factor "capital" in the regions represented in order to increase its contribution to GRP [14-15].

\section{Conclusion}

Note that the application of this technique is possible for all factors of production in order to determine the total resource potential of the regions. In the future, it is proposed to select indicators characterizing such factors as "labor", "land" and "entrepreneurship", and to identify the presence of concentration of certain types of resources in the regions of the central federal district. Such an assessment will make it possible to determine not only the availability of resources, but also their involvement in the reproduction process, which makes it possible to predict potential intersectoral interaction manifested in the form of cluster structures in order to reform the country's economy in the direction of import substitution.

\section{References}

1. G. E. Halkos, N. G.Tzeremes Journ.of Polic. Model., 31(6), 847-862 (2009) https://doi.org/10.1016/j.jpolmod.2009.08.003

2. A. Mottaeva, J. Ćetković Advances in Intelligent Systems and Computing, 692, 1151-1159 (2018) doi: 10.1007/978-3-319-70987-1_123

3. Sh. Dobzinski, N. Nisan, S. Oren, Games Econ. Behav (2018) https://doi.org/10.1016/j.geb.2018.02.010

4. E. V. Lukin, T. V. Uskova, Ec. A. Soc. Chang.: F., Tr., Forec., 11(6), 26-40 (2018) DOI: 10.15838/esc.2018.6.60.2

5. Y. G. Lavrikova, L. M. Averina Soc. Chang.: F., Tr., Forec., 3(39), 85-99, (2015) DOI: 10.15838/esc/2015.3.39.7

6. M. B. Petrov, Vestnik UrFU 2, 113-124 (2010)

7. E. Ganebnykh, A. Mottaeva, T. Larinina, E.Petrova, MATEC Web of Conferences, 170, 01044 (2018) doi.org/10.1051/matecconf/201817001044

8. E. Bessonova, O. Mereshchenko, ECON. AN.-XXI, 163(1-2), 91-94 (2017)

9. E. A. Ploskonosova, Tech. a. techn. o. f. prod., 1, 157-162 (2014)

10. O. S. Sukharev, E. N. Voronchikhina, Ec. Que., 6, 29-47 (2018)

11. O. A. Donichev, D. Yu. Fraimovich, S. A. Grachev, Ec. A. Soc. Chang.: F., Tr., Forec., 11(3), 84-99 (2018)

12. D.Radushinsky, A. Mottaeva, L. Andreeva, G. Dyakova, IOP Conf. Series: Earth and Environmental Science 90, 012137 (2017) doi :10.1088/1755$1315 / 90 / 1 / 012218$

13. E. Akhmetshin, V. Vasilev, et al. IBIMA 2018: Innovation Management and Education Excellence through Vision 2020, 6395-6401 (2018)

14. A. Mottaeva, E. Vasilyeva, MATEC Web of Conferences, 239, 04019 (2018)

15. N. Khairullina, O. Ustinova et al., International Journal of Economics and Financial Issues, 6(S2), 110-116 (2016) 